\title{
POTENTIAL POSITIVE IMPACTS OF DIGITALIZATION OF CONSTRUCTION-PHASE INFORMATION MANAGEMENT FOR PROJECT OWNERS
}

\author{
SUBMITTED: January 2020 \\ REVISED: January 2021 \\ PUBLISHED: January 2021 \\ EDITOR: Esther Obonyo \\ DOI: $10.36680 /$ j.itcon.2021.001
}

\section{Qais K. Jahanger, Ph.D., Lecturer}

Civil Engineering Department, College of Engineering, Mustansiriyah University, Baghdad - Iraq; Formerly, Ph.D. Candidate, School of Civil and Construction Engineering, Oregon State University, USA; qais.jahanger@uomustansiriyah.edu.iq

\author{
Joseph Louis, Ph.D., Assistant Professor \\ School of Civil and Construction Engineering, Oregon State University, Corvallis, OR 97331, USA; \\ joseph.louis@oregonstate.edu
}

\section{Catarina Pestana, Ph.D., Instructor}

School of Civil and Construction Engineering, Oregon State University, Corvallis, OR 97331, USA; catarina.pestana@oregonstate.edu

David Trejo, Ph.D., P.E., Professor

School of Civil and Construction Engineering, Oregon State University, Corvallis, OR 97331, USA. david.trejo@oregonstate.edu

\begin{abstract}
SUMMARY: Productivity in the US construction industry has been widely reported to be on the decline and among several causes identified, the lack of innovation in project management practices has been described as having led to lost productivity, especially in the face of growing project complexity and the increasing need for enhanced stakeholder collaboration. Digitalization has the potential to improve project management and thus help in reversing this decline in productivity. However, several public agencies have not fully adopted construction or document management software, known herein as digital construction-phase information management (DCIM) systems. This paper identifies the potential positive impacts that stem from the use of such technologies towards project management with the goal of incentivizing their use. Eighteen such potential positive impacts of DCIM systems on project management for public owners were identified and verified using a systematic literature review and statistical analysis of survey responses from industry professionals. Furthermore, a comparison between two representative types of public owners was performed to identify how owner preferences vary in the industry. The results show an overall agreement amongst end-users regarding the identified potential positive impacts of DCIM systems. The result further identified the top five potential positive impacts with a significant strong agreement. The analysis also identified differences in what impacts were most significant to the two types of tested subpopulations. These findings can enhance project owners' understanding of the potential positive impacts brought using digitalization in the project administration and delivery process. This research can also enhance DCIM systems developers' understanding of the needs of end-users, particularly project owners, and guide the development of future solutions for project administration and delivery.
\end{abstract}

KEYWORDS: Digitalization, Construction Phase, Information Management, Project Owners

REFERENCE: Qais K. Jahanger, Joseph Louis, Catarina Pestana, David Trejo (2021). Potential positive impacts of digitalization of construction-phase information management for project owners. Journal of Information Technology in Construction (ITcon), Vol. 26, pg. 1-22, DOI: 10.36680/j.itcon.2021.001

COPYRIGHT: (C) 2021 The author(s). This is an open access article distributed under the terms of the Creative Commons Attribution 4.0 International (https://creativecommons.org/licenses/by/4.0/), which permits unrestricted use, distribution, and reproduction in any medium, provided the original work is properly cited. 


\section{INTRODUCTION}

Construction is a broad and fragmented industry that has been noted to struggle to meet project requirements in terms of cost, time, and productivity (Woetzel et al., 2017, Teicholz, 2013). In the USA, public agencies are responsible for constructing, operating, and maintaining important public properties, especially infrastructure and facilities (Tymvios and Gambatese, 2016). For instance, state departments of transportation (DOTs) are mostly responsible for infrastructure such as highways and bridges, while public universities (PUs) are usually responsible for facilities such as educational buildings and research laboratories. Thus, they act as owners to capital-intensive infrastructure or facilities development projects. These agencies face numerous challenges in ensuring that their respective infrastructure functions efficiently (Geddes and Madison, 2017, Ichniowski, 2019). On one hand, there is a growing demand on these public agencies and infrastructure due to increasing urbanization and population growth (LeClair, 2018, Cho, 2019); while on the other, these agencies face challenges due to increasing costs of construction and limited resources (Cho, 2018, Cho, 2019, Ichniowski, 2019). There are also functional and administrative challenges such as complicated or prolonged work processes and exhausting or redundant managerial activities (Case and White, 2016, O'Brien et al., 2017, Sillars et al., 2017) that hinder the performance of their responsibilities. ASCE (2017) notes that the estimated funding gap for infrastructure in the USA by 2025 will be $\$ 2$ trillion and have called for innovative approaches for construction stakeholders, including public agencies, to innovate and improve their project management and business practices to reduce costs, save time, and improve operations productivity.

One class of solutions that has been proposed to overcome these challenges is the use of novel technologies including digital information technologies and automation tools for the management of construction documents and processes (Weisner et al., 2017, D'Amico, 2012). Digitalization using construction or document management software that provides functions such as contract administration, document management, workflow management, and activities tracking and control, in particular, has the potential to improve project administration and delivery process. Thus, digitalization could help public agencies overcome many of the aforementioned functional and administrative challenges in managing capital-intensive projects (ASCE Grand Challenge, 2017). While contractors use such tools relatively extensively, a review of public owners indicates that these agencies have not either deployed or fully used digital systems on projects, especially in the construction phase (Shah et al., 2017, FHWA, 2018, Sillars et al., 2017). There is significant uncertainty within organizations regarding the implementation feasibility and potential benefits of digitalization and this has negatively affected the adoption of digitalization systems (Shah et al., 2017, Sillars et al., 2017).

Of the project delivery process, construction is generally the longest and most expensive phase. Furthermore, it is also the phase requiring the collaboration between the most number of stakeholders (contractors, suppliers, etc.). Thus, it is expected to be relatively more challenging to successfully implement digitalization in this phase. For these reasons, the emphasis of this paper is on the digitalization of construction-phase information management on projects by project owners, especially public agencies. Public agencies are mainly studied in this research due to their focus on capital-intensive projects and lack of research regarding their usage of software systems. Two types of software systems are commonly used to digitalize construction phase information management: construction management software (CMS), such as AASHTOWare Project and Primavera P6; and electronic document management systems (EDMS), such as ProjectWise and Doc Express (Shah et al., 2017). While CMS is typically used for workflow management of daily tasks during construction, EDMS is usually used for engineering and contractual document management, especially as a central repository or database for projects (Sillars et al., 2017). These software systems are called Digital Construction-phase Information Management (DCIM) systems in this paper. The authors define the DCIM system as a combination of software systems that can be used to digitize documents of projects, and digitally manage and document the projects' activities and workflow in the construction phase.

Based on the review of existing literature about DCIM systems which is presented in Section 2, the authors identify the following specific gaps in knowledge that serve to guide this research:

1. Non-consideration of project owner's utilization of software: While previous research has examined contractors' utilization of such systems, there is a lack of information on owners' utilization of software systems for managing construction projects. This is even though owners have a significant role in project management, especially for public projects; and the fact that such technology that caters exclusively to 
owners do exist. Project owners, especially public agencies, usually have different managerial roles and thus different needs than contractors on projects.

2. Lack of research about the importance of digitalization for project owners: While there exists a significant body of knowledge regarding potential positive impacts of digitalization for contractors, there is a lack of objective research which confirms the potential positive impacts of digitalization for project owners (Lu et al., 2015). This could negatively affect the adoption of DCIM systems by project owners, especially public agencies. Since project owners are involved in the administration, inspection, and commissioning of construction projects, it is necessary to obtain their perspective on DCIM systems to increase overall industry productivity.

In light of these knowledge gaps regarding DCIM systems, the goal of this paper is to identify and assess potential positive impacts of digitalization of construction-phase information management for project owners with the larger goal of increasing and facilitating its adoption, especially by public agencies. This goal will be accomplished through the pursuit of three specific objectives as noted below:

1. Objective 1: Identify potential positive impacts of digitalization on owners' project administration and delivery process.

2. Objective 2: Determine levels of agreement regarding the identified potential positive impacts of digitalization by groups of project owners.

3. Objective 3: Determine the effect of type of agency on agreement levels. This significantly contributes to the body of knowledge due to the variety of agencies (organizations) that comprise project owners.

Objective 1 was accomplished using a systematic literature review that is described in Section 2.2, while Objectives 2 and 3 were accomplished using a survey-based methodology that is described in Section 3 of this paper. Following this description of the methodology, the collection and analysis of data is presented along with discussion of results. Finally, the conclusions of this study are presented in this paper.

\section{BACKGROUND AND LITERATURE REVIEW}

Digitalization is a broad concept that encompasses processes and tools that utilize digital technologies data to transform a business model and provide new revenue and value-producing opportunities (Prause, 2016, i-SCOOP, 2016). Digitalization can be applied to any part of the project administration and delivery process in the construction industry (Shah et al., 2017). One such digitalization effort is "e-Construction" that was launched by the Federal Highway Administration (FHWA) to promote the use of digital information management technologies, mobile devices, and document automation tools in DOTs towards improving the project administration and delivery process (Weisner et al., 2017). Although e-Construction is the only digitalization effort that will be presented in this literature review, its concepts and methods are representative of and applicable to other public agencies such as PUs, departments of public works, and water resources departments. This is because the US public agencies are, in general, similar in their organizational structures or in how they obtain public funding and deliver projects. The FHWA's Center for Accelerating Innovation (2016) defines e-Construction as "the collection, review, approval, and distribution of highway construction contract documents in a paperless environment." It is a paperless approach to project delivery that includes the following three major components:

1. Electronic submission of all construction documentation by all stakeholders

2. Electronic document routing and approvals (e-signature)

3. Digital management of all construction documentation in a secure environment allowing distribution to all project stakeholders through mobile devices (Center for Accelerating Innovation, 2016)

Shah et al. (2017) identified eight opportunities for improvement to the DOTs project delivery process that collectively represents the key components necessary to develop a comprehensive e-Construction program for DOTs. Shah et al. (2017) categorized these e-Construction improvement opportunities into four categories (preconstruction, construction, post-construction, and cross-cutting) based on project delivery phases, as shown in Table 1. 
TABLE 1: e-Construction Improvement Opportunities

\begin{tabular}{|l|l|l|}
\hline Pre-construction & Construction & Post-construction \\
\hline $\begin{array}{l}\text { (1) Digital and Intelligent } \\
\text { Plans, Specifications, and } \\
\text { Estimates (PS\& E) }\end{array}$ & $\begin{array}{l}\text { (3) Digital Review of Contract Documents (by } \\
\text { using secure Electronic “Bidding" System) }\end{array}$ & $\begin{array}{l}\text { (6) Requirements of Digital } \\
\text { As-Built Records }\end{array}$ \\
\hline $\begin{array}{l}\text { (2) Electronic Bidding and } \\
\text { Contract Award }\end{array}$ & $\begin{array}{l}\text { (4) Digital Project Construction Management } \\
\text { (by using CMS) }\end{array}$ & \\
\hline & $\begin{array}{l}\text { (5) Digital Management of Construction } \\
\text { Documentation (by using EDMS) }\end{array}$ & \\
\hline \multicolumn{3}{|c|}{ (7) Digital Signatures } \\
\hline \multicolumn{3}{|c|}{ (8) Mobile Devices } \\
\hline \multicolumn{3}{|c|}{ Cross-cutting } \\
\hline
\end{tabular}

The table shows that project owners can utilize various digital technologies in different phases of projects and thus benefit from them to improve the project delivery process, especially construction.

\subsection{Potential Positive Impacts of Digitalization}

Since the late 1990s, research has been conducted to identify the potential positive impacts of using DCIM systems on projects. However, most of the research in this domain has focused on contractors (Lu et al., 2015) using webbased systems (Deng et al., 2001, Zhiliang et al., 2004, Mak, 2001, Martínez-Rojas et al., 2015). For example, Nitithamyong and Skibniewski $(2003,2006,2007)$ conducted research to study web-based project management systems (WPMS) that can be rented by construction firms from service providers. As part of the research, they identified six perspectives (strategic, schedule/time, cost, quality, risk, and communication) that can be used to evaluate the WPMS performance. Thirty six benefits were identified to be used as potential measures to evaluate the six perspectives, and thus the WPMS performance on projects. Stewart and Mohamed $(2003,2004)$, and Mohammed and Stewart (2003) identified five performance perspectives of project information management that were improved by using web-based project information management systems on large construction projects. These perspectives were operational, benefits, technology/systems, strategic competitiveness, and user orientation.

In the same context, many other researchers, such as Weippert et al. (2002), Thorpe (2003), Vaughan et al. (2013), and Hasan et al. (2019) conducted research to study DCIM systems utilization on projects by contractors. Weippert et al. (2002), surveyed stakeholders on a case study project to rank their satisfaction regarding seven IT implementation perspectives for implementing internet-based construction project management (ICPM) systems on a remote construction project in Australia. Based on their ranking, these perspectives are: (1) information technology (IT), which is also the center of the framework that the other perspectives linked to it, (2) project management, (3) user utility (4) strategic positioning, and (5) value-adding, (6) project organization, and (7) benefits. Similarly, Thorpe (2003) also studied the implementation of ICPM systems (known also as online remote construction management (ORCM)) on a remote construction project in Australia, yet from a user view of ORCM, not a research perspective. Thorpe (2003) reported results, especially ranks of satisfaction regarding seven IT implementation perspectives, similar to Weippert et al. (2002).

Vaughan et al. (2013) used a cost-benefit analysis to identify the quantitative and qualitative benefits of using a web-based construction information management system (CIMS), especially with mobile devices, on a university library project. The benefits of implementation were found to include (1) a 11.6\% gain in management efficiency; (2) 7.5 hour decrease in total weekly hours worked by each of the studied staff on management activities; (3)1.5 hours of the earlier clerical time returned to the project in form of value-added planning time; and (4) potential savings of 12 to 38 days' worth of travel time to gather documents for each user on a 2-year project. The intangible (qualitative) benefits included (1) increased employee retention and reduced stress, and (2) ability of CIMS to address root causes of rework. Hasan et al. (2019) also studied the implementation of web-based project management by construction organizations, especially with the use of mobile devices, and thus called mobile information and communication technology (Mobile ICT). The study aimed to investigate the main consequences of using Mobile ICT on construction project management and how this use can ultimately affect construction productivity. Hasan et al. (2019) identified five main consequences on project management: four positive and one negative. They are, respectively, improved communication and work relationship, better management of construction defects, better information management on-site, improved work planning, and distraction and waste of time. Hasan et al. (2019) reported that improved communication and work relationship and better management 
of construction defects are the two consequences that can mainly increase construction productivity. However, distraction and waste of time can adversely affect construction productivity (Hasan et al., 2019).

\subsection{Identification of Potential Positive Impacts}

In light of the gaps in knowledge relating to the non-consideration of project owner's utilization and importance of DCIM systems, the first objective of this research seeks to identify potential positive impacts of digitalization on owners' project administration and delivery process. Towards this end, a systematic literature review was conducted, based on Siddaway (2014), which consisted of six steps under two main parts, (1) studies selection; and (2) data extraction and synthesis.

\subsubsection{Studies Selection}

The first step of the studies selection part is identification. Fig. 1 shows a schematic of the studies selection and shows the number of manuscripts assessed at each step.

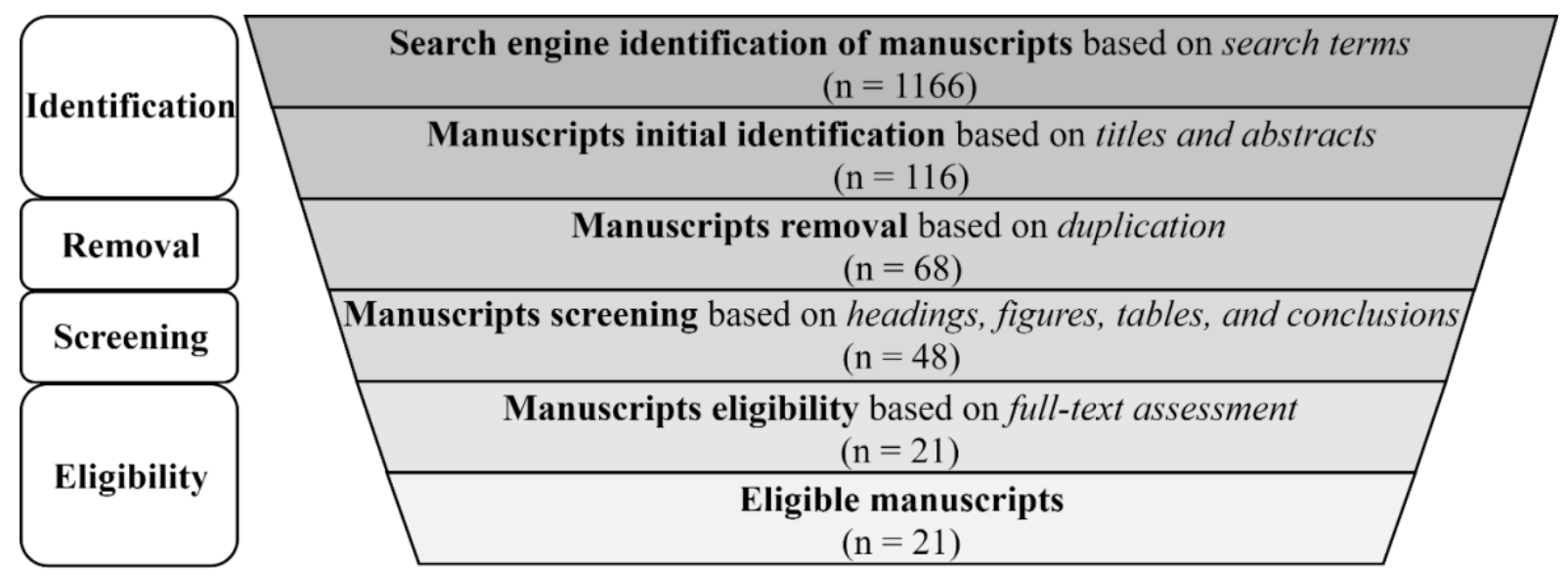

FIG. 1: Part I of the Systematic Literature Review: Studies Selection

Identification of relevant papers was performed by first creating search terms relevant to the research goal. Three online research databases (Google Scholar, American Society of Civil Engineers (ASCE), and FHWA) were selected to search for manuscripts. Selection of databases this research was based on obtaining information regarding the state of practice in the US construction. Therefore, the selected academic databases were Google Scholar, which provides search results from around the world; ASCE, which is an important scholarly database that publishes research focused on the US construction industry. Additionally, FHWA was selected because it is an industry-based database that publishes reports or articles which are directly related to the selected domain of study. Based on the search terms, the search engines of the three online sources identified 1166 papers, articles, or reports. At this stage, the relevancy of each article was directly examined online based on its title and abstract, resulting in 68 relevant manuscripts after removal of duplicates. Next, these articles were screened further for relevancy based on information in headings, figures, tables, and conclusions resulting in the exclusion of 20 studies that were deemed irrelevant. The final step performed a full-text eligibility assessment based on specified inclusion/ exclusion criteria. Fifteen research papers and six FHWA reports or articles were identified as relevant and eligible for this research because it included sets of benefits and improvements that could be considered for a DCIM system.

\subsubsection{Data Extraction and Synthesis}

This research required the identification of an initial set of PPIs of DCIM systems for owners to obtain their perceptions about them. These were extracted from the 21 selected studies. This study defines PPIs as any potential benefits or improvements a DCIM system can bring to an owner's project administration and delivery process. Thus, 348 potential benefits or improvements that could be PPIs from a DCIM system were extracted from the literature: 295 from 15 research papers and 53 from six FHWA reports and articles. These benefits were then qualitatively synthesized prior to the development of a survey questionnaire for the owners. Fig. 2 shows the 
general steps of data extraction and synthesis, and the reduction in the number of PPIs with each of the data synthesis sub-step.

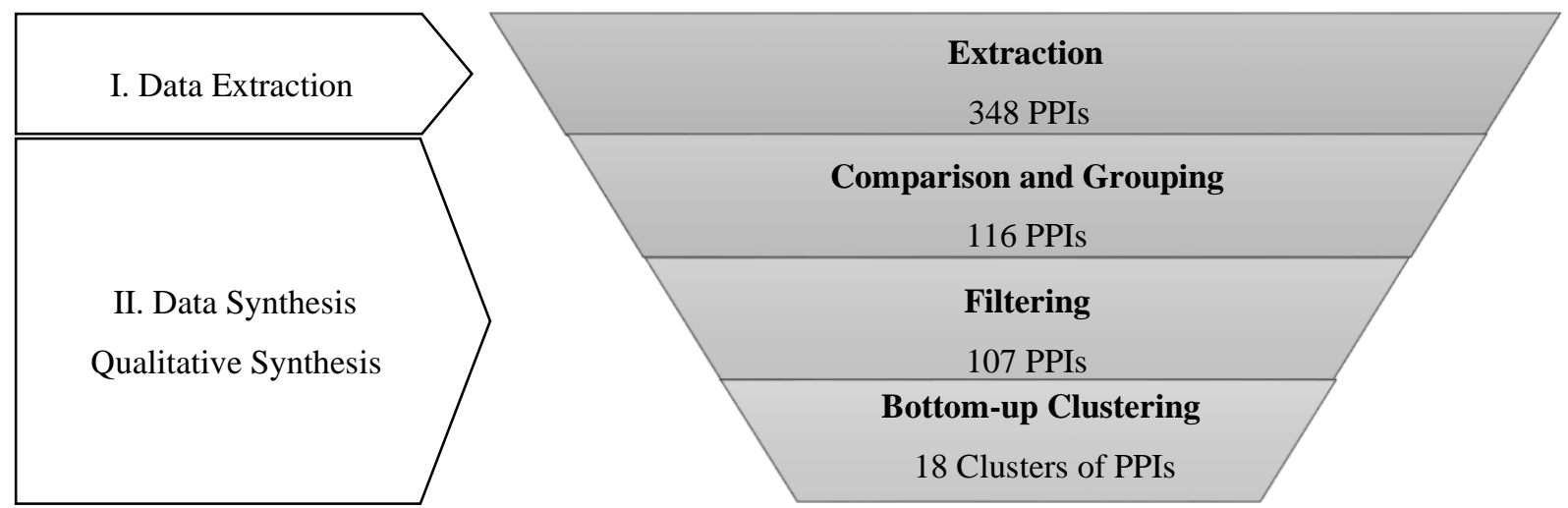

FIG. 2: Part II of the Systematic Literature Review: Data Extraction and Synthesis

The synthesis step started by examining and identifying similar extracted PPIs for grouping, following which the 116 PPIs were filtered to exclude the irrelevant PPIs. Nine PPIs, such as appropriateness for application/function, suitability for site conditions, and level and frequency of training provided, were excluded because these were not potential benefits or improvements. Finally, a bottom-up clustering technique was used to subjectively treat the wide range of the grouped PPIs. The bottom-up clustering technique enables researchers to cluster objects (data or information) based on their similarity. The process was iteratively performed to cluster the grouped PPIs to a sufficiently representative set of PPIs from the literature. For example, three of the grouped PPIs ([i] digitization optimizes utilization of staff; [ii] IT software enables improvement in overall organizational efficiency and competitiveness on projects; and [iii] improving project team's computer literacy) were clustered in two iterations to form a larger impact called: "DCIM systems improve staff's performance in projects for the organization" due to the similarity in their impact. In another instance of clustering, six grouped PPIs ( [i] decreases number of RFIs; [ii] workforce motivation; [iii] trades notified daily of work list items; [iv] plans/specifications/RFIs available to project members in mobile electronic format; [v] QA/QC deficiencies automatically create action items for responsible trades; and [vi] digitization enables signing electronic documents remotely) were clustered in three iterations to form the PPI "DCIM systems facilitate workflow management and progress on projects". Eighteen PPIs were synthesized from this process. No further PPIs could be determined for inclusion in the survey. Table 2 lists these PPIs with their references, which will be referred to henceforth using the terms identified in bold text. The subtext under the title of the PPI indicates an illustrative example of the PPI for better understanding by the survey user. 


\begin{tabular}{|c|c|c|c|c|c|c|c|c|c|c|c|c|c|c|c|c|c|c|c|c|c|}
\hline & & & & & & & sear & rch I & Pap & & & & & & & & le & $\begin{array}{l}\mathbf{R e} \\
\mathrm{es}\end{array}$ & ef & & \\
\hline PPI & 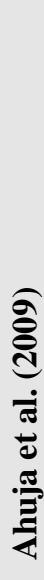 & 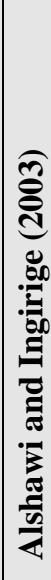 & 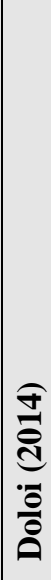 & 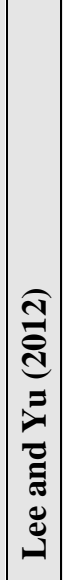 & 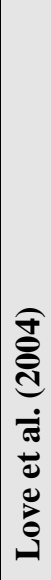 & 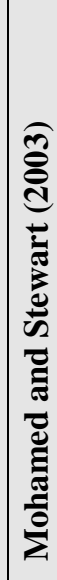 & 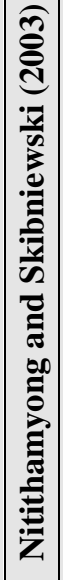 & 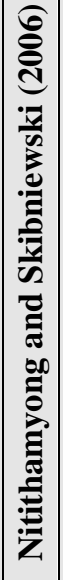 & 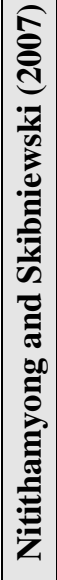 & 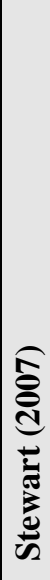 & 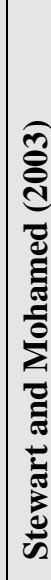 & 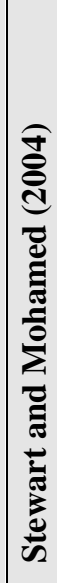 & 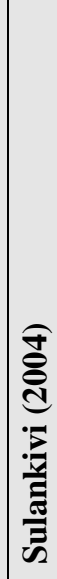 & 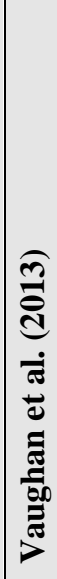 & 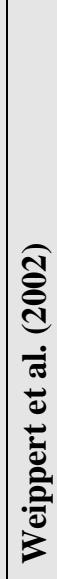 & 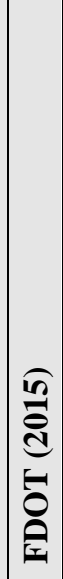 & 孚 & 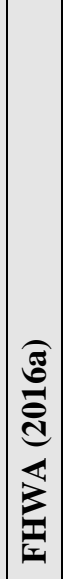 & 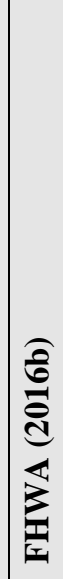 & 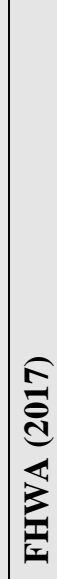 & 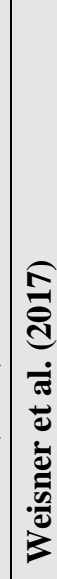 \\
\hline $\begin{array}{l}\text { 1) DCIM systems could improve the financial abilities of the } \\
\text { organization. } \\
\text { For instance, application of DCIM systems could competitively benefit owners by } \\
\text { attracting more sophisticated parties (e.g., contractors) leading to lower bids and thus the } \\
\text { ability to do more business. }\end{array}$ & & & & & $\bullet$ & $\bullet$ & $\bullet$ & $\bullet$ & $\bullet$ & $\bullet$ & $\bullet$ & $\bullet$ & & & & $\bullet$ & & & & $\bullet$ & \\
\hline $\begin{array}{l}\text { 2) DCIM system could lead to long-term strategic benefits to the } \\
\text { organization. } \\
\text { For example, digitalization could improve construction program growth and success, coulc } \\
\text { increase capability for national cooperation, could enhance disaster recovery, could } \\
\text { improve the organization's image in the industry, etc. }\end{array}$ & & & & & & $\bullet$ & & $\bullet$ & $\bullet$ & $\bullet$ & $\bullet$ & $\bullet$ & & & & & & & & & \\
\hline $\begin{array}{l}\text { 3) DCIM systems improve staff's performance in projects for the } \\
\text { organization. } \\
\text { For instance, using DCIM systems optimizes utilization of staff, enables efficient } \\
\text { organization on projects, and improves a project team's computer literacy. }\end{array}$ & & & & & & & & & & $\bullet$ & $\bullet$ & 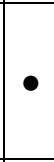 & & 0 & & & & & & & \\
\hline $\begin{array}{l}\text { 4) DCIM systems improve contract administration of organizations. } \\
\text { For example, payments to contractors can be more accurate and quicker by using DCIM } \\
\text { systems. It improves cash flow. }\end{array}$ & 0 & & & & $\bullet$ & & & $\bullet$ & & $\bullet$ & $\bullet$ & $\bullet$ & & & & $\bullet$ & $\bullet$ & & & & \\
\hline
\end{tabular}


5) DCIM systems enable significant cost savings for the organization. For instance, DCIM systems reduce the need for travel, phone usage, physical documentation and storage, etc.

6) DCIM systems improve work processes in the organization.

For instance, DCIM software facilitates streamlining of processes, and/or enhances

processing of progress claims, and/or enhances integration with other business functions

(core systems) such as accounting and asset management systems, etc.

7) DCIM systems improve communication capabilities on projects. For instance, DCIM systems reduce barriers in communications, and reduce the need for physical and/or direct communication such as face-to-face meeting, faxes, mails, etc. 8) DCIM systems facilitate tracking project activities for project management and control.

For instance, DCIM systems improve maintaining updated and organized records,

especially for tracking purposes, and owners can verify that issues are being addressed and closed out in a timely manner.

9) DCIM systems improve the efficiency of documentation within the organization.

For instance, application of DCIM systems facilitates further standardization of reports or forms within agencies, generates reports for distribution with photo and comments attached, enables instant status updates on issues, improves the accuracy and quality of data and documents, etc.

10) DCIM systems facilitate documentation in the office as well as on the job site.

For instance, DCIM systems make completion and approval of the digital daily field reports easier than the traditional paper reports, eliminate the need to transfer hand-written notes to electronic format, prevent documents (e.g. material tickets) from being lost, etc.

11) DCIM systems improve transparency of information on projects.

For instance, a DCIM system is a centralized hub for project information, plans, and issues, and these documents are available for viewing by all authorized persons. This information is compiled and available to be disseminated to other projects.

12) DCIM systems significantly improve document management

\section{during construction.}

For instance, DCIM systems allow for the easy access and distribution of documents to other parties, allow for the retrieval of project information from many locations, decrease in document multiple handling, etc.

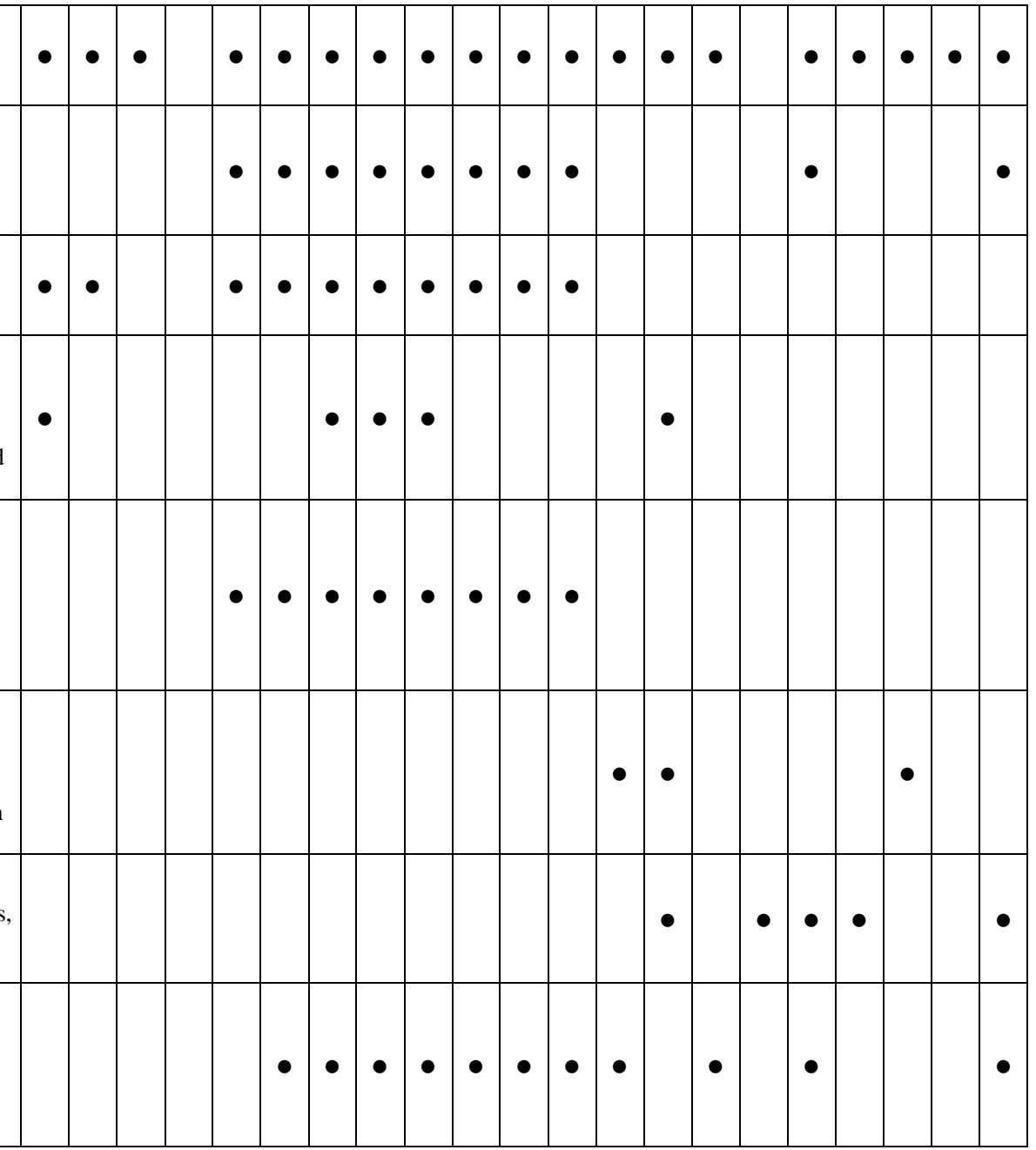


13) DCIM systems improve risk mitigation on projects.

For instance, the application of DCIM systems reduces numbers of claims on projects, helps in conforming to contracts, enables audit trails for risk mitigation, and helps to operate in a secure environment.

14) DCIM systems improve teamwork cooperation on projects. For instance, DCIM systems facilitate and support project alliance and industry partnerships, improve business relations and satisfaction on projects, enable necessary parties to observe and communicate on issues, facilitate decision making, etc.

15) DCIM systems facilitate workflow management and progress on projects.

For instance, plans, specifications, RFIs are available to project members in a mobile electronic format, action items regarding $\mathrm{QA} / \mathrm{QC}$ deficiencies can be automatically created and distributed for responsible trades, and with a digital signature, documents can be signed remotely.

16) DCIM systems improve construction management in terms of carrying out the right tasks to attain desired project goals (duration, budget, etc.).

For instance, DCIM systems enable a robust management program and thus increase the effectiveness of management by helping them to cary out the DCIM systems can effectively help management to identify erots in documents and thus reduce the risk of rework or delaying a project goal.

17) DCIM systems improve construction management in terms of minimizing waste of time and effort when working to accomplish managerial tasks.

For instance, by using DCIM systems, management can save time due to less clerical tasks, more efficiency in data processing and document approval, ability to quickly sort and filter issues, ability of faster reporting and feedback on projects, etc. DCIM systems further enable management to speed up document processing by reducing repetitive activities and to enhance processing accuracy by reducing errors.

18) DCIM systems improve worktime distribution of construction management on projects.

For instance, using DCIM systems allow project managers to spend more time on managerial tasks rather than clerical tasks, digitalization also enables field staff to have more time on the job site instead of the office.

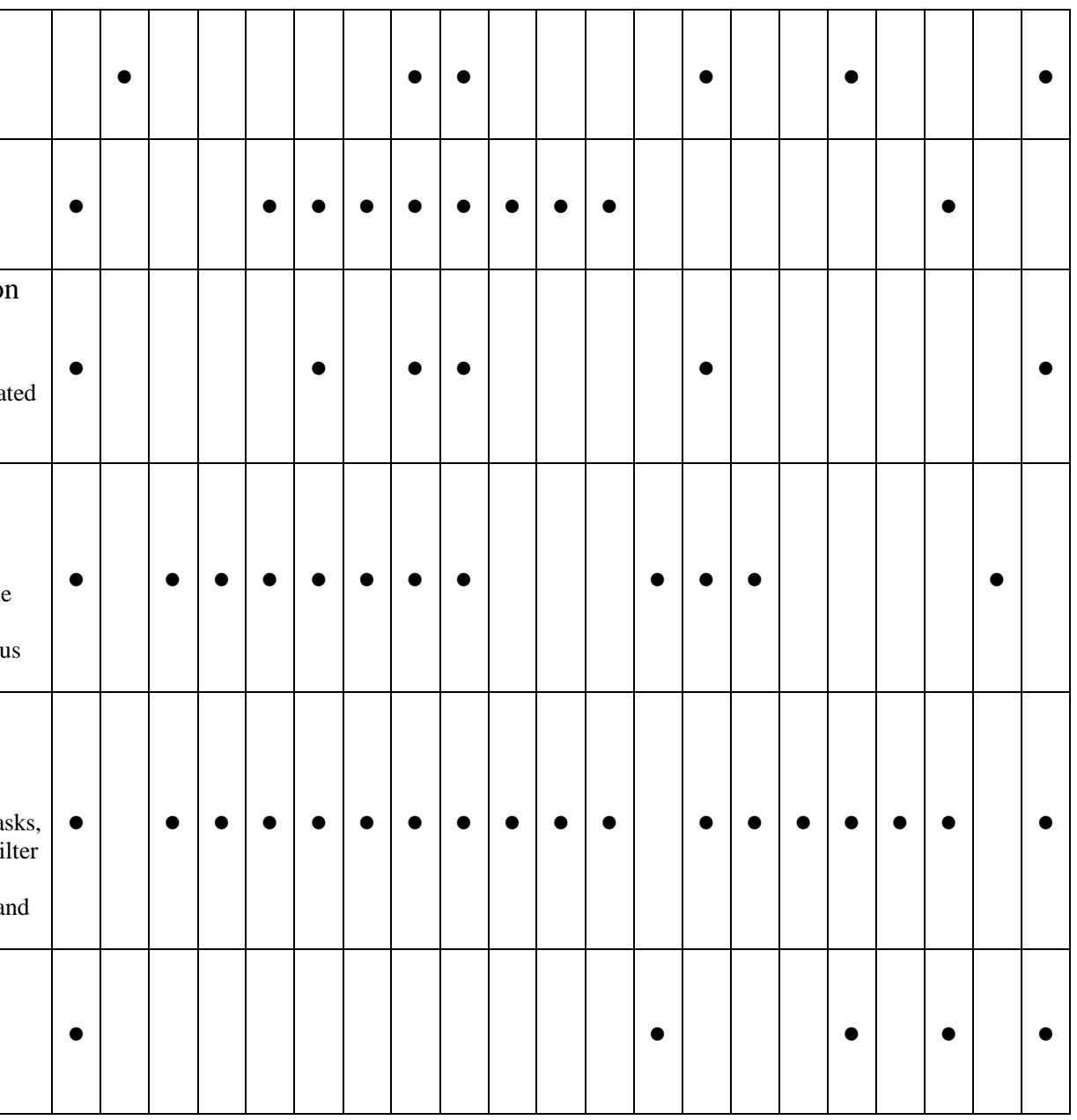

Objective 1 of this research was accomplished in this subsection and the findings are presented above in the table. The research methodology to fulfill Objectives 2 and 3 are explained in the next section. 


\section{RESEARCH METHODOLOGY}

To achieve the research goal and fill gaps in the literature regarding owners' perceptions of PPIs of DCIM systems, the methodology created by the authors and shown in Fig. 3 is followed to answer the following research questions (1 and 2) that are associated with Objectives 2 and 3 respectively.

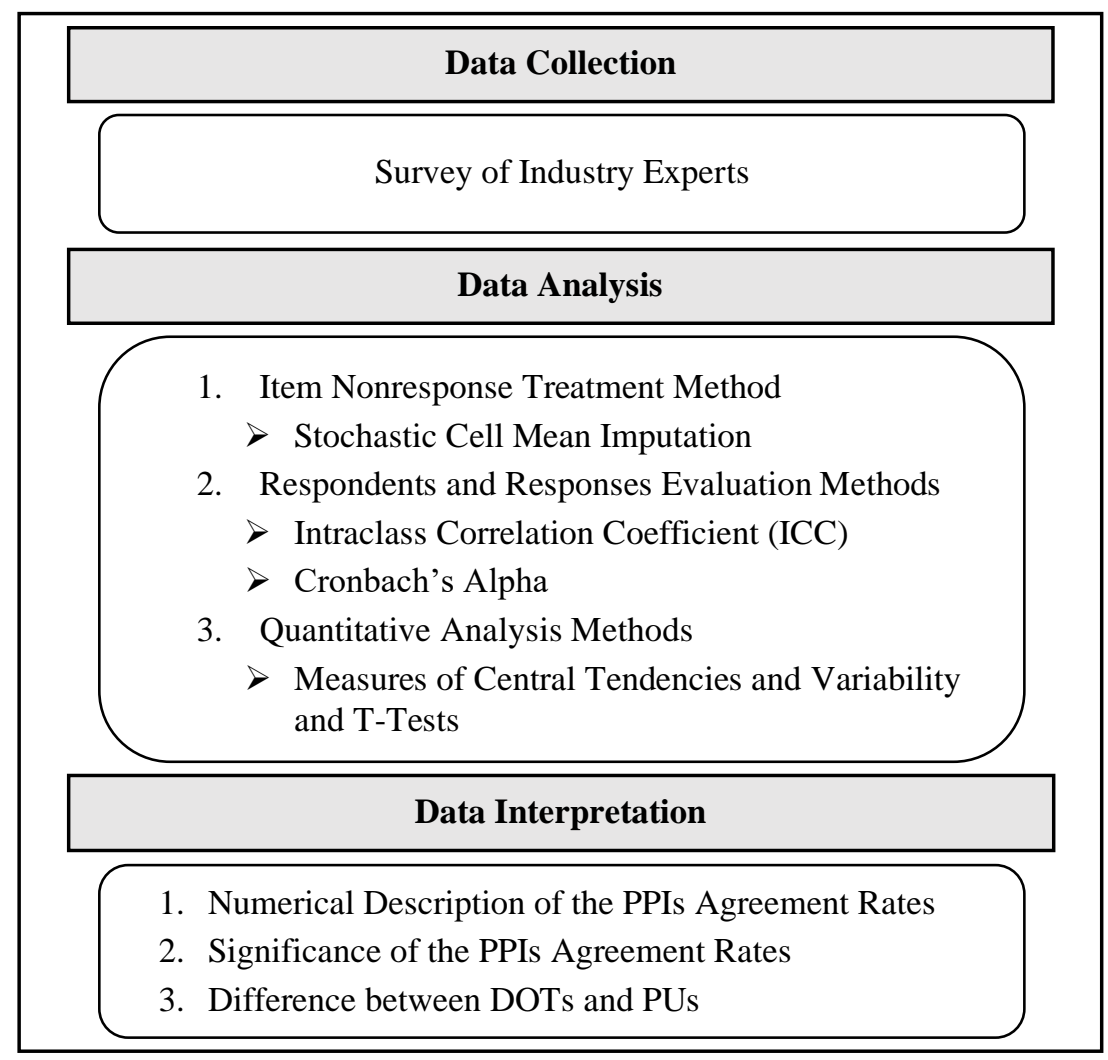

\section{FIG. 3: Research Methodology}

Question 1: Is there strong agreement among owners' project administration and delivery staff regarding each PPI of digitalization? To answer this question, two levels of hypothesis testing using one-sample t-tests were conducted.

The level 1 null hypothesis $\left(H 1_{0}\right)$ that was tested for each PPI was: There is no minimum agreement regarding the tested PPI among the population represented by the respondents. The alternative hypothesis $\left(H 1_{1}\right)$ was: There is at-least minimum agreement regarding the tested PPI among the population represented by the respondents. Mathematically, the null and alternative hypotheses are:

Null hypothesis: $H 1_{0}: \mu \leq 60 \%$

Alternative hypothesis: $H 1_{1}: \mu>60 \%$

The level 2 null hypothesis $\left(H 2_{0}\right)$ that was tested for each PPI was: Although there is minimum agreement, there is no strong agreement regarding the tested PPI among the population represented by the respondents. The alternative hypothesis $\left(H 2_{1}\right)$ was: There is strong agreement regarding the tested PPI among the population represented by the respondents. Mathematically, the null and alternative hypotheses are:

Null hypothesis: $H 2_{0}: \mu \leq 80 \%$

Alternative hypothesis: $H 2_{1}: \mu>80 \%$

Question 2: Does the staff of different groups of project owners (e.g., DOTs versus PUs) have different perceptions (convictions) regarding PPIs of digitalization? To answer this question, two-sample t-tests were conducted. 
The null hypothesis $\left(H_{0}\right)$ that was tested for each PPI was: There is no difference in the mean agreement rates between DOTs and PUs. The alternative hypothesis $\left(H_{1}\right)$ was: There is a difference in the mean agreement rates between the DOTs and PUs. Mathematically, the null and alternative hypotheses are:

$$
\begin{aligned}
& \text { Null hypothesis: } H_{0}: \mu_{D O T s}-\mu_{P U s}=0 \\
& \text { Alternative hypothesis: } H_{1}: \mu_{D O T S}-\mu_{P U s} \neq 0
\end{aligned}
$$

As seen in Fig. 3, the methodology consists of three main stages: data collection, data analysis, and data interpretation. The data collection is performed through a survey deployed to industry experts. The data collected through the survey was quantitatively analyzed in the second stage using reliability evaluation, and hypothesis testing prior to interpretation of results to draw research conclusions. Each of these phases is explained in the following subsections.

\subsection{Data Collection}

To answer the research questions and verify the PPIs of DCIM systems, a survey instrument was deployed. This was selected as the primary data collection method because it is most appropriate to collect data from subject matter experts that are geographically located all over the US. An explanation of the survey development and collection process follows.

\subsubsection{Survey Design and Piloting}

Data were collected through a self-administered web-based questionnaire. The questionnaire consists of question related to demographic information of respondents and questions related to respondents' perception of PPIs, including an open-ended question to obtain PPIs that were not included in the survey.

For each PPI, the respondents were asked to rate their agreement with the PPI using a slider that ranged from one (lowest level of agreement with statement) to 100 (highest level) with increments of 1 degree. To further guide the respondent and enable the choice of both parametric and nonparametric statistical analysis of the data, the slider was divided into five bins: strongly disagree from one to 20, disagree from 21 to 40, neither agree nor disagree from 41 to 60, agree from 61 to 80, and strongly agree from 81 to 100. This enables the use of parametric statistical techniques, especially t-test, to analyze the data (agreement rates) because the data is numerical (continuous) and has thresholds (limits of bins) needed to formulate hypotheses. Also, because the data can also be categorized based on the five equal-length intervals, it can be considered categorical (ordinal) data that can be subject to nonparametric statistical methods. To improve the clarity, quality, and relevancy of the survey, it was pilot tested through multiple steps and with different subject matter experts (Ph.D. candidates, professors, a survey specialist, and an industry practitioner) prior to final deployment.

\subsubsection{Survey Distribution and Collection}

The first step in the survey distribution was to specify the sample that was going to receive the questionnaire. Due to the nature of the research, the homogeneous purposive sampling technique was used to select the sample because the numbers of people who are available and can serve as primary data sources are limited. Purposive sampling is a non-probability sampling method in which a sample is chosen by researchers based on characteristics of a population and the objective of the study (Dudovskiy, 2019, Crossman, 2018). The targeted population of this research is the project administration and delivery staff of project owners. To get a sample that could fairly represent various project owners, two groups of public agencies that are different in size and capabilities as well as in type and complexity of projects they manage, were targeted in this research. The two groups are:

1. Departments of Transportation (DOTs): The DOTs were selected because they generally are large public agencies that perform construction projects to build, maintain, and develop horizontal transportation infrastructure, especially highways. Employees that are part of the roadway design and project administration within the division of highway, especially those involved in the eConstruction, were targeted in the DOTs of the 50 states and District of Columbia (DC).

2. Public Universities (PUs): The PUs were selected because they also are a type of public agencies and usually perform construction projects to build, maintain, and develop facilities (usually vertical) ranging from educational and residential buildings to advanced research and sport facilities. The employees involved with facilities development and administration, especially project managers who are responsible for capital projects, were targeted in two to three PUs in 
each of the 50 states and the DC. The selected PUs were the largest on-campus (4-year) public higher education institution based on the undergraduate school enrollment. College Information Peterson's website (Peterson's, 2019) was used to identify the PUs.

Qualtrics software was used to digitize the questionnaire and distribute it online to the two samples. Details on sample sizes for the DOTs and the PUs and response rates are provided in the results section.

\subsection{Data Analysis}

This section describes the statistical methods used to treat, evaluate, and analyze the data collected from the surveys.

\subsubsection{Item Nonresponse Treatment Method}

Stochastic cell mean imputation is a technique that can be used to treat missing data (item nonresponse) in surveys based on the other available data. In cell mean imputation, respondents are divided into groups (cells) based on known variables. Then, the arithmetic mean of the values provided by the responding units (respondents) in any cell is directly substituted for each missing value (item) in that cell (Lohr, 2010). The variables were used in this research to divide the cells are respondents' years of experience and job titles. In the stochastic version that was followed in this paper, some random noise is added to adjust also for some of the missing variability. In this version, instead of a cell mean, a draw from a normal distribution centered at the cell mean with some specified standard deviation is used to substitute each missing value in that cell (Lohr, 2010). The stochastic cell mean imputation technique was selected because it substitutes missing data based on means (averages) and standard deviations and the data analysis methods (descriptive statistics and t-tests) in this paper depend on means and standard deviations.

\subsubsection{Respondents and Responses Evaluation Methods}

Intraclass correlation coefficient (ICC) and Cronbach's alpha coefficient were first used to evaluate the reliability of respondents and responses, as described below.

\subsubsection{Intraclass Correlation Coefficient}

The ICC technique was used to assess the reliability of the respondents in terms of rating agreement and consistency. The ICC technique enables researchers to measure the absolute agreement among the raters, the consistency of raters in term of rating, or both (Shrout and Fleiss, 1979). Thus, a decision can be made to use all the available data or not. A higher ICC coefficient indicates a higher similarity of rates and thus a higher agreement or more consistency among respondents (Cicchetti, 1994). The guidelines used for interpreting ICC measures can be found in Cicchetti (1994).

\subsubsection{Cronbach's Alpha Coefficient}

Cronbach's alpha coefficient (aka Alpha) enables researchers to measure the internal consistency (or reliability) of rates (composite scores) observed for a group of related items, such as questions of a math test, with one underlying construct (Goforth, 2015, Bland and Altman, 1997). This allows for validating the test or scale for further use. However, Cronbach's alpha should be measured each time the test or scale used to see if it remains in general stable over multiple studies (Tavakol and Dennick, 2011, Connelly, 2011). Alpha was used in this research to measure the internal consistency of the PPIs as a tool to assess the overall positive impact (usefulness) of DCIM systems. The alpha scores were interpreted according to the guidelines provided in George and Mallery (2011).

\subsubsection{Quantitative Analysis Methods}

After ensuring the reliability of the responses, measures of central tendencies and variability were used to describe various characteristics of the collected data (agreement rates). These descriptive statistics were used to summarize the agreement rates regarding the 18 PPIs and present them in a simple, meaningful way to enable answering the two questions of this research.

T-tests were used to draw inferences about the targeted population (project owners' project administration and project delivery staff). One-sample t-tests were used to answer Question 1: the research question regarding the agreement level among the population regarding each PPI of digitalization. Two-sample t-tests were used to answer Question 2: the research question regarding the difference in perceptions regarding the PPIs between the 
two different types of agencies. The t-tests were usable because the data are numerical and continuous, the sample sizes are sufficiently large to assume approximate normality for the samples means, and the responses are assumed independent from each other within samples and between samples (Ramsey and Schafer, 2013, Lohr, 2010).

The one-sample t-test is a parametric statistical technique that can be used to draw an inference regarding a mean of a population variable when the variance of the population variable is unknown (Ramsey and Schafer, 2013). The one-sample t-tests were used to test hypotheses developed based on Question 1 of the research and thus draw inferences regarding the overall population as well as regarding the DOTs and the PUs subpopulations separately.

To test the difference in means of a variable between two populations (or subpopulations) when the variable variances are unknown and not assumed equals, Welch's two-sample t-test can be used (Ramsey and Schafer, 2013). The Welch's two-sample t-tests were used to test hypotheses developed based on Question 2 of the research and thus draws inferences regarding the differences in mean PPIs between the DOTs and the PUs as two separate subpopulations.

\section{RESULTS AND DISCUSSION}

The section first presents the demographics of the survey respondents, followed by the assessment of respondents' generality and reliability, and the PPIs internal consistency. Then, the quantitative analysis results using t-tests are presented and discussed.

\subsection{Survey Respondent Demographics}

Ninety-three construction project administration and delivery staff of public agencies participated in the survey. Table 3 details sample sizes and response rates for DOT respondents, PU respondents, and the entire sample size and response rate.

TABLE 3: Sample Size and Response Rate

\begin{tabular}{|l|l|l|l|}
\hline Owners group & Sample & Responses & Response Rate \\
\hline DOTs & 233 & 53 & $22.75 \%$ \\
\hline PUs & 643 & 40 & $6.22 \%$ \\
\hline All & 876 & 93 & $10.62 \%$ \\
\hline
\end{tabular}

\subsubsection{Geographic Distribution of Respondents}

To ensure a reasonable representation of all the nine geographical divisions in the USA as defined by the US Census Bureau (US Census Bureau, 2017), the survey was sent to a DOT sample and a PU sample in every state. Although responses were not received from some of the states and DC, and there was overlap between some of the DOTs and PUs respondents' states; the responses fairly represented all the US nine divisions. In term of states, the 53 responses from the DOTs represented 30 states, and the 40 responses from the PUs represented 28 states. Table 4 details the number of responses in each of the US nine divisions.

TABLE 4: Number of Responses in the US Nine Divisions

\begin{tabular}{|l|l|l|l|l|}
\hline Division & States & All & DOTs & PUs \\
\hline Pacific & Alaska, California, Hawaii, Oregon, and Washington & 23 & 14 & 9 \\
\hline Mountain & $\begin{array}{l}\text { Arizona, Colorado, Idaho, Montana, Nevada, New Mexico, } \\
\text { Utah, and Wyoming }\end{array}$ & 15 & 7 & 8 \\
\hline West North Central & $\begin{array}{l}\text { Iowa, Kansas, Minnesota, Missouri, Nebraska, North Dakota, } \\
\text { and South Dakota }\end{array}$ & 11 & 8 & 3 \\
\hline West South Central & Arkansas, Louisiana, Oklahoma, and Texas & 10 & 4 & 6 \\
\hline East North Central & Illinois, Indiana, Michigan, Ohio, and Wisconsin & 10 & 6 & 4 \\
\hline East South Central & Alabama, Kentucky, Mississippi, and Tennessee & 3 & 1 & 2 \\
\hline South Atlantic & $\begin{array}{l}\text { Delaware, District of Columbia, Florida, Georgia, Maryland, } \\
\text { North Carolina, South Carolina, Virginia, and West Virginia }\end{array}$ & 11 & 8 & 3 \\
\hline Middle Atlantic & New Jersey, Pennsylvania, and New York & 4 & 2 & 2 \\
\hline New England & $\begin{array}{l}\text { Connecticut, Maine, New Hampshire, Massachusetts, Rhode } \\
\text { Island, and Vermont }\end{array}$ & 6 & 3 & 3 \\
\hline
\end{tabular}




\subsubsection{Construction, DCIM Systems, and Owner-based Work Experience of Respondents}

The demographic results regarding the respondents' experience in the construction industry showed that almost all the respondents ( $88.2 \%$ ) have a significant amount of experience (10 years or above) in the industry, especially working at owner agencies. In addition to their experience in the construction industry, almost all the respondents (92.5\%) also expressed their familiarity with DCIM systems, especially CMS. These factors support the respondents' ability to provide experience-based agreement rating for the PPIs.

\subsection{Approximate Distribution of Organizations' DCIM Systems Use}

Respondents were asked about the software their agencies have used and if used, for the duration of usage. Table 5 shows DCIM systems options and how many times each were selected by DOT or PU respondents. For the DOTs, ProjectWise was the most used software, followed by AASHTOWare Project. However, one respondent did not have experience with any DCIM software. Regarding the approximate duration of use, DOT respondents reported that, on average, 11.5 years was the approximate duration of using (or piloting) one or more of DCIM systems. For the PUs, e-Builder was the most used software followed by Primavera P6. However, seven respondents working for seven different PUs responded that DCIM systems were not used and thus provided no or zero approximate duration of use. Few other respondents responded the reliance of their PUs on the contractor's system. The PU respondents in general identified that they use one software and, on average, used this software for approximately 6.5 years.

TABLE 5: Software Used by Respondents' Agencies Based on Selections of the Respondents

\begin{tabular}{|l|l|l|l|}
\hline$\#$ & DCIM Systems (Software) & DOTs & PUs \\
\hline 1 & ProjectWise & 36 & 0 \\
\hline 2 & Procore & 0 & 7 \\
\hline 3 & AASHTOWare Project & 29 & 0 \\
\hline 4 & Primavera P6 & 22 & 8 \\
\hline 5 & Doc Express & 17 & 0 \\
\hline 6 & e-Builder & 4 & 12 \\
\hline 7 & PlanGrid & 6 & 7 \\
\hline 8 & Other software* & 16 & 15 \\
\hline 9 & None & 1 & 7 \\
\hline Total & & 131 & 56 \\
\hline
\end{tabular}

* DOT examples are SharePoint and Headlight. PU examples are Projectmates, Bluebeam Revu, Autodesk BIM360, and PMWeb.

For any agency (a DOT or a PU) that had use time of two or more respondents, the average of the approximations was taken. The durations provided for 26 PUs and the 30 DOTs shows that the PUs are generally more recent in utilizing DCIM systems compared to the DOTs.

\subsection{Agreement and Consistency Assessment of Respondents}

The absolute agreement among respondents as a group of random raters and the consistency of their rating were assessed for all the respondents as well as for the DOTs and PUs separately. ICC technique was used. Since the variables of interest (PPIs) will be measured and tested by averages of agreement rates (mean ratings) of a group of respondents, the absolute agreement coefficient $(\operatorname{ICC}(2, \mathrm{k}))$ and the consistency coefficient $(\operatorname{ICC}(3, \mathrm{k}))$ for average scores were calculated. High values of $(\operatorname{ICC}(2, \mathrm{k}))$ and $(\operatorname{ICC}(3, \mathrm{k}))$ support the reliability of the average values of agreement rates and thus support the reliability of respondents as a group of random raters (representatives) from their population and as a fixed group of consistent raters. RStudio software was used to calculate the ICC coefficients. Table 6 details ICC coefficients and their interpretation for all the respondents, the DOT respondents, and the PU respondents.

TABLE 6: ICC Coefficients and Interpretation for All, DOT, and PU Respondents

\begin{tabular}{|l|l|l|l|l|}
\hline Respondents & $\begin{array}{l}\text { ICC(2,k)) } \\
(\text { Absolute Agreement) }\end{array}$ & $\begin{array}{l}\text { Interpretation } \\
\text { (Cicchetti, 1994) }\end{array}$ & $\begin{array}{l}\text { (ICC(3,k)) } \\
\text { (Consistency) }\end{array}$ & $\begin{array}{l}\text { Interpretation } \\
\text { (Cicchetti, 1994) }\end{array}$ \\
\hline All & 0.902 & Excellent & 0.954 & Excellent \\
\hline DOTs & 0.84 & Excellent & 0.918 & Excellent \\
\hline PUs & 0.84 & Excellent & 0.92 & Excellent \\
\hline
\end{tabular}


As it can be seen in the table above, the absolute agreement regarding mean ratings among all respondents (and DOT and PU groups) and the consistency of the respondents' mean ratings are both excellent. Thus, the responses (mean ratings) from all the respondents as a group, as well as DOTs and PUs, are reliable and can be all used.

\subsection{Reliability Assessment of Potential Positive Impacts}

The internal consistency reliability of the PPIs was also assessed for the DOTs, the PUs, and all the respondents. A high measure of alpha means the reliability of the multiple items (PPIs) as a related group to evaluate (measure) the same underlying construct (overall usefulness of DCIM systems). R studio software was used to calculate the Cronbach's alpha coefficients. Table 7 shows Cronbach's alpha and its interpretation for all the PPIs responses, the PPIs responses from the DOTs, and PPIs responses from the PUs.

TABLE 7: Cronbach's Alpha and Interpretation for All, DOT, and PU Responses

\begin{tabular}{|l|l|l|}
\hline PPIs Agreement Rates & $\begin{array}{l}\text { Cronbach's Alpha } \\
\text { (Internal Consistency) }\end{array}$ & $\begin{array}{l}\text { Interpretation } \\
\text { (George and Mallery, 2011) }\end{array}$ \\
\hline All & 0.96 & Excellent \\
\hline DOTs & 0.95 & Excellent \\
\hline PUs & 0.96 & Excellent \\
\hline
\end{tabular}

The internal consistency of the PPIs based on the respondents' agreement rates (responses) is excellent. Thus, the PPIs are a reliable group to be considered when evaluating DCIM systems.

\subsection{Agreement Rates of Potential Positive Impacts}

The quantitative analysis results are presented and discussed based on the research questions. This subsection presents and discusses results of the numerical descriptive analysis and the hypothesis testing (test of significance) analyses. The numerical descriptive analysis results include a summary of the collected data and a description of its main statistics (arithmetic means). Results of the hypothesis testing analyses include tests results interpretation and inferences regarding the targeted population as well as the two subpopulations.

\subsubsection{Numerical Description of Agreement Rates}

To answer the research questions and thus fulfill Objectives 2 and 3 of this paper, the collected agreement rates for the PPIs from the survey were summarized using averages. Table 8 shows the mean agreement rates of the PPIs for all responses together as well as for the DOT and PU responses individually.

TABLE 8: Means of the PPIs Agreement Rates

\begin{tabular}{|l|l|l|l|l|}
\hline$\#$ & Potential Positive Impact (PPI) & \multicolumn{3}{|c|}{ Mean } \\
\cline { 3 - 5 } & & All & \multicolumn{3}{|l|}{ DOTs } & PUs \\
\hline 1 & Efficiency of documentation & $84.81^{\mathrm{ab}}$ & $87.42^{\mathrm{ab}}$ & $81.35^{\mathrm{a}}$ \\
\hline 2 & Contract administration & $84.56^{\mathrm{ab}}$ & $87.53^{\mathrm{ab}}$ & $80.63^{\mathrm{a}}$ \\
\hline 3 & Work processes & $84.49^{\mathrm{ab}}$ & $86.64^{\mathrm{ab}}$ & $81.65^{\mathrm{a}}$ \\
\hline 4 & Tracking project activities & $84.08^{\mathrm{ab}}$ & $85.81^{\mathrm{ab}}$ & $81.78^{\mathrm{a}}$ \\
\hline 5 & Long-term strategic benefits & $82.7^{\mathrm{ab}}$ & $85.57^{\mathrm{abc}}$ & $78.9^{\mathrm{ac}}$ \\
\hline 6 & Staff's performance & $82.63^{\mathrm{a}}$ & $85.40^{\mathrm{ab}}$ & $78.97^{\mathrm{a}}$ \\
\hline 7 & Documentation in the office as well as on the job site & $82.42^{\mathrm{a}}$ & $85.79^{\mathrm{abc}}$ & $77.95^{\mathrm{ac}}$ \\
\hline 8 & Transparency of information on projects & $81.73^{\mathrm{a}}$ & $83.64^{\mathrm{ab}}$ & $79.2^{\mathrm{a}}$ \\
\hline 9 & Document management during construction & $81.52^{\mathrm{a}}$ & $82.21^{\mathrm{a}}$ & $80.6^{\mathrm{a}}$ \\
\hline 10 & Workflow management and progress & $80.95^{\mathrm{a}}$ & $81.75^{\mathrm{a}}$ & $79.88^{\mathrm{a}}$ \\
\hline 11 & Communication capabilities & $79.38^{\mathrm{a}}$ & $84.70^{\mathrm{abc}}$ & $72.33^{\mathrm{ac}}$ \\
\hline 12 & Financial capabilities & $74.97^{\mathrm{a}}$ & $79.57^{\mathrm{ac}}$ & $68.88^{\mathrm{ac}}$ \\
\hline 13 & Construction management in terms of minimizing waste of time and effort & $74.37^{\mathrm{a}}$ & $79.36^{\mathrm{ac}}$ & $67.75^{\mathrm{ac}}$ \\
\hline 14 & Construction management in terms of carrying out the right tasks & $73.65^{\mathrm{a}}$ & $74.70^{\mathrm{a}}$ & $72.25^{\mathrm{a}}$ \\
\hline 15 & Worktime distribution of construction management & $72.74^{\mathrm{a}}$ & $77.17^{\mathrm{ac}}$ & $66.88^{\mathrm{ac}}$ \\
\hline 16 & Teamwork cooperation & $71.31^{\mathrm{a}}$ & $75.66^{\mathrm{ac}}$ & $65.55^{\mathrm{c}}$ \\
\hline 17 & Cost savings & $69.55^{\mathrm{a}}$ & $77.81^{\mathrm{ac}}$ & $58.6^{\mathrm{c}}$ \\
\hline 18 & Risk mitigation & $67.51^{\mathrm{a}}$ & $69.32^{\mathrm{a}}$ & 65.1 \\
\hline
\end{tabular}




\begin{tabular}{|l|l|l|l|l|}
\hline$\#$ & Potential Positive Impact (PPI) & \multicolumn{3}{|c|}{ Mean } \\
\cline { 3 - 5 } & & All & DOTs & PUs \\
\hline & Overall mean (expected value) of the PPIs & 78.52 & 81.67 & 74.34 \\
\hline
\end{tabular}

a: Significant evidence $(p$-value $<0.05)$ against a null hypothesis that there is no minimum agreement

b: Significant evidence ( $p$-value $<0.05$ ) against a null hypothesis that there is no strong agreement

c: Significant evidence $(p$-value $<0.05)$ against a null hypothesis that there is no difference in means

The summaries presented in the Table 8 are discussed in the Discussion of Analysis and Results subsection.

\subsubsection{Significance of Agreement Rates}

Hypothesis testing (test of significance) using one-sample t-tests were used to draw inferences to answer Question 1 in this paper, two levels of hypothesis testing were conducted to draw a general conclusion regarding the respondents' population based on the significance of the survey responses: Level 1 and Level 2, as described below.

\subsubsection{Level 1 Hypothesis Testing}

Eighteen t-tests, with significance level $(\alpha)=0.05$, to test the Level 1 null hypothesis were conducted for the 18 PPIs based on all the responses. Significant evidence ( $p$-value < 0.05$)$ was found against the null hypothesis for each of the 18 PPIs. Thus, it can be inferred that there is at least a minimum agreement among the respondents' population regarding all the 18 PPIs. These PPIs are marked using an (a) in Table 8 . To make inferences regarding the two types of agencies separately, thirty-six other t-tests were conducted for the 18 PPIs: Eighteen t-tests based on the DOT responses and eighteen t-tests based on the PU responses. For DOTs, significant evidence ( $p$-value < 0.05 ) was found against the null hypothesis for each PPI. Thus, it can be inferred that there is at least a minimum agreement among the DOT subpopulation regarding all the 18 PPIs. They are also marked using an (a) in Table 8.

However, this was not the case for the PUs. Significant evidence ( $p$-value $<0.05$ ) was found against the null hypothesis for 15 PPIs. Thus, it can also be inferred that there is at least a minimum agreement among the PU subpopulation regarding each of the 15 PPIs. These PPIs are also marked using an (a) in Table 8. No minimum agreement among the PU subpopulation can be inferred regarding the other three PPIs.

While having a minimum agreement makes a PPI desirable, it might not be enough to be qualify that PPI as a key driver to promote adoption or further investment in digitalization; especially as DCIM systems can be expensive to purchase and, require continuous effort, training, and time while in use. Therefore, further investigation is needed to test whether there is also strong agreement among the respondent population regarding the PPIs or not. A null hypothesis was developed based on that, and one-sample t-tests were conducted to draw conclusions. The tests and results are presented in the next section.

\subsubsection{Level 2 Hypothesis Testing}

Eighteen t-tests, with significance level $(\alpha)=0.05$, to test the Level 2 null hypothesis were conducted for the 18 PPIs based on all the responses. Significant evidence ( $p$-value < 0.05$)$ was found against the null hypothesis for five PPIs. Thus, it can be inferred that there is strong agreement among the respondents' population regarding each one of these five PPIs. These PPIs are marked using a (b) in Table 8. For the remaining PPIs, no significant evidence ( $p$-value $\geq 0.05$ ) was found against the null hypothesis. Thus, a strong agreement cannot be inferred regarding each one of them.

Similar to the testing performed in Level 1, two sets of one-sample t-tests were separately conducted for the data collected from the two groups of agencies to draw inferences regarding them. Eighteen t-tests were conducted to test the null hypothesis based on the DOT responses, and $15 \mathrm{t}$-tests were conducted to test the null hypothesis based on the PU responses. Three PPIs from the PUs were not tested because they were already insignificant at Level 1 of the testing.

For DOTs, significant evidence ( $p$-value < 0.05 ) was found against the null hypothesis for nine PPIs. Thus, it can be inferred that there is strong agreement regarding these nine PPIs among DOT subpopulation. These nine PPIs are also marked using a (b) in Table 8 . For the remaining nine PPIs, no significant evidence ( $p$-value $\geq 0.05$ ) was found against the null hypothesis. Thus, it cannot be inferred as strongly agreed on these nine PPIs among the DOT subpopulation. For the PUs, no significant evidence ( $p$-value $\geq 0.05$ ) was found against the null hypothesis 
for any of the tested PPIs. Thus, it cannot be inferred that there is a strong agreement for any of the 15 PPIs among the PU subpopulation.

It can be seen that there is a difference in perception (general conviction) between the two groups regarding the PPIs of DCIM systems. While the DOT subpopulation strongly agrees on nine of the 18 PPIs and agrees, at least minimally, on the remaining PPIs, the PU subpopulation only agrees on 15 PPIs and does not agree, even minimally, on the remaining PPIs. Even for the PPIs that both subpopulations generally agree or do not strongly agree on, there could still be significant statistical differences due to differences in agreement rates and variances. However, significant statistical differences between the two groups cannot be inferred based on individual onesample t-tests. This needs to be statistically tested and inferred based on two-sample t-tests. These tests are explained in the next section.

\subsubsection{Difference between the Two Subpopulations}

Eighteen two-sample t-tests, with significance level $(\alpha)=0.05$, to test the null hypothesis regarding the difference between the two groups of public agencies were conducted for the 18 PPIs based on the DOT responses (sample one from subpopulation one) and the PU responses (sample two from subpopulation two). Significant evidence ( $p$-value < 0.05) was found against the null hypothesis for eight PPIs. Thus, it can be inferred that there are significant statistical differences in mean agreement rates between DOTs and PUs. These eight PPIs are marked with (c) in Table 8. For the remaining 10 PPIs, no significant evidence ( $p$-value $\geq 0.05$ ) was found against the null hypothesis that there is no difference in mean agreement rates.

\subsection{Discussion of Results}

As can be seen in Table 8, 10 PPIs have agreement rates greater than $80 \%$ and this indicates that there is strong agreement regarding each one of these 10 PPIs. The other eight PPIs have rates lesser than $80 \%$ but still above $60 \%$. Thus, there is still moderate to a high level of agreement among project owners regarding these PPIs.

Individually, it can be seen in Table 8 that the PPIs with highest levels of agreement are the efficiency of documentation, contract administration, and work processes. It is noted that that these three PPIs, especially contract administration and work processes, are perceived to be an improvement that directly relates to an organization (a project owner). This indicates that the respondents strongly agree that DCIM systems can improve an organization's overall business process and project administration through improvement in documentation efficiency, contract administration, and work processes. On the other hand, it can be seen in Table 8 that the three least agreed on PPIs are teamwork cooperation, cost savings, and risk mitigation. The least and third least agreed on PPIs are related to projects and its overall administration, especially when external parties (e.g., a contractor) are involved. The second least agreed on PPI is related to the expected financial benefits to an organization due to cost saving, especially from administrative and documentation costs. Although the respondents do not strongly agree that DCIM systems can help in teamwork cooperation, cost saving, and risk mitigation, the respondents still moderately agree on these PPI but with the highest variation in the response rate.

As two separate subpopulations, the DOTs appear to be more optimistic than the PUs regarding the usefulness of DCIM systems. While the DOT subpopulation strongly agrees on nine PPIs, the PU subpopulation does not strongly agree on any PPI. This variation indicates differences between the two groups of public agencies in term of general convictions regarding PPIs of DCIM systems. These differences could be due to differences in size and capabilities and differences in type and complexity of projects. When the differences in PPI agreement rates were statistically tested between the two subpopulations based on means, eight significant statistical differences were found in mean agreement rates. This show that differences do exist between the two groups of agencies regarding significant part of the PPIs. No significant statistical differences in mean agreement rates were found for the 10 remaining PPIs. These findings shed light on which aspects of project administration and delivery can be benefits based on the type and size of owner organization and also provide insights to developers for areas to work on when targeting different groups of owners.

Grouping the PPIs based on thematic similarity of expected improvements from DCIM systems and development of a framework for DCIM systems implementation that enables reaching these main groups can help project owners to successfully implement DCIM systems and guide the implementation to reach desired improvement (group(s) of PPIs). This can also help in minimizing the differences in implementation between different groups of project owners and thus minimizing the differences (disagreement) regarding the PPIs. 


\section{SUMMARY AND CONCLUSIONS}

For project owners, especially public agencies, many DCIM systems are available and can be utilized to improve project administration and the delivery process during the construction phase. Nevertheless, the adoption of such systems by many public agencies is not yet as high as expected. This is unfortunate as construction productivity is greatly influenced by the management of the construction process. The lack of adoption by public agencies is a result of owners and owners' representatives not having a firm understanding of important factors that influence systems' implementation and PPIs that can serve as key drivers and an evaluation tool. The specific goal of this paper is to identify and assess PPIs of digitalization of construction-phase information management for project owners with the larger goal of increasing and facilitating its adoption, especially by public agencies. To identify the PPIs of DCIM systems, a systematic literature review was conducted to identify and extract information (benefits or improvements) that could be considered as PPI from using such systems. Then, the bottom-up clustering technique was used to qualitatively synthesize 348 -extracted information to 18 comprehensive but concise PPIs of DCIM systems. Finally, a survey questionnaire was used to rate and thus verify the PPIs using statistical analysis.

Using data (agreement rates) collected from 93 employees of two large groups of project owners (DOTs and PUs); statistical analyses provided support and validation for the 18 PPIs. Results of the measures of central tendencies (arithmetic means) show that there is, on average, a moderate agreement regarding all the PPIs and that the efficiency of documentation is the most agreed on PPI and risk mitigation is the least agreed on PPI. Results ( $p$ values) of the tests of significance using one-sample t-tests show that the population represented by the respondents agree, at least minimally, on each one of the 18 PPIs. When a higher level of agreement (strong agreement) was also tested, the results show that the respondents' population strongly agree on five PPIs. However, when the population was divided into two subpopulations based on the agency type (DOTs and PUs), and the subpopulations were separately tested using one-sample t-tests, there was a difference in convictions between the two agency types regarding many of the PPIs. The two-sample t-tests show that there are significant statistical differences in mean agreement rates between the two subpopulations regarding eight PPIs.

This research shows that many aspects of the owners' project administration and delivery process could be significantly improved when implementing DCIM systems, especially the following:

1. Efficiency of documentation, including standardization of reports or forms within agencies, generation of work reports, and the ability to updates instantly on project issues and status

2. Contract administration, including quicker and more accurate payments to contractors

3. Work processes, including streamlining of processes, processing of progress claims, and/or the integration with other business functions (core systems) such as accounting and asset management systems

4. Tracking project activities, including the ability to maintain updated and organized records and verification of issues that are being addressed or closed in a timely manner

5. Long-term strategic benefits, including construction program growth and success, capability for cooperation, disaster recovery, the organization's image in the industry, and others

The main contribution of this paper to the body of knowledge and industry is showing that there are 18 PPIs for project owners from the implementation of DCIM systems (digitalization) and thus project administration and delivery process of owners can be significantly improved, especially in five aspects. These findings should be key drivers that motivate public agencies to further adopt and use DCIM systems as well as broader investment in construction digitalization. Project owners can also use the identified PPIs as an evaluation tool to assess the system performance within their organizations and on their construction projects. The other important contribution is showing that there are differences between the two types of agencies in perceptions regarding the PPIs and thus differences, especially significant, regarding their agreement rates. This should encourage DCIM systems developers to improve their software systems to satisfy further the aspects of project administration and delivery process that are not strongly agreed on.

The following limitations are acknowledged for the research performed followed by recommendations for future work. 
(1) Missing data due to nonresponse: Nonresponse in terms of units (respondents) and items (questions) is a common limitation of data collection through surveys. While unit nonresponse in this study represents more than $89 \%$ of the sample, the collected 93 responses were sufficiently large to conduct the analyses and draw inferences, as noted by Ramsey and Schafer (2013). Stochastic cell mean imputation was used to treat a few item nonresponse $(1.5 \%)$ in the PUs data. (2) Consideration of only public agencies: In this research, public agencies were only considered without private owners because they have similarities in how they obtain public funding and deliver projects, as well as having similar organizational structures. (3) Non-use of qualitative methods: The goal of the paper necessitated quantitative methods for data collection and analysis. Nevertheless, an open-ended question was included in the questionnaire to collect additional information. Some respondents provided additional information (qualitative responses); however, the qualitative responses were limited with no consensus, especially to be analyzed and presented.

Private owners should be considered in future work to first analyze differences between public and private, and to help increase the impact of digitalization on project performance throughout the industry. Future work should also consider qualitative methods for data collection such as interviews and thus qualitative analysis techniques such as coding. This method could capture more PPIs that were not available from a systematic literature review. An important future work is to identify and rank potential influencing factors that can affect the successful implementation of DCIM systems on projects by project owners. Identifying potential influencing factors and ranking them represent an important research goal in this topic. This could be conducted using research planning and methodology similar to this paper.

\section{REFERENCES}

Ahuja V., Yang J. and Shankar R. (2009). Benefits of Collaborative ICT adoption for building project management. Construction Innovation, 9, 323-340.

Alshawi M. and Ingirige B. (2003). Web-enabled project management: an emerging paradigm in construction. Automation in Construction, 12, 349-364.

ASCE Grand Challenge. (2017). Managing Construction Electronically [Online]. ASCE. Available: https://collaborate.asce.org/ascegrandchallenge/resources/focusareas/focus-lcca/managing-constructionelectronically [Accessed].

Bland J. M. and Altman D. G. (1997). Statistics Notes: Cronbach's Alpha. BMJ: British Medical Journal, 314 , 572-572.

Case D. and White G. (2016). WSDOT construction: The headlight inspection tool pilot project Utah $e$ Construction Conference - March 2016. Salt Lake City, Utah.: Utah Department of Transportation.

Center for Accelerating Innovation. (2016). States choose e-Construction to save time and money. Innovator [Online], 53. Available: http://www.fhwa.dot.gov/hfl/innovator/e-version/issue_53/3dIssue/.

Cho A. (2018). Highway funds are hard to find. Engineering News-Record. 990 Park Center Dr, Visita, CA.

Cho A. (2019). California looks at transportation funding. Engineering News-Record. 990 Park Center Dr, Vista, CA: bnp media.

Cicchetti D. V. (1994). Guidelines, criteria, and rules of thumb for evaluating normed and standardized assessment instruments in psychology. Psychological Assessment, 6, 284-290.

Connelly L. M. (2011). Cronbach's Alpha. MedSurg Nursing.

Crossman A. (2018). Understanding Purposive Sampling: An Overview of the Method and Its Applications [Online]. ThoughtCo. Available: https://www.thoughtco.com/purposive-sampling-3026727 [Accessed].

D'Amico E. (2012). On the road to digitization. Engineering News-Record. bnp media.

Deng Z. M., Li H., Tam C. M., Shen Q. P. and Love P. E. D. (2001). An application of the Internet-based project management system. Automation in Construction, 10, 239-246.

Doloi H. (2014). Rationalizing the implementation of web-based project management systems in construction projects using PLS-SEM. Journal of Construction Engineering and Management, 140, 1-10. 
Dudovskiy J. (2019). Purposive sampling [Online]. Research Methodology. Available: https://researchmethodology.net/sampling-in-primary-data-collection/purposive-sampling/ [Accessed].

FDOT (2015). e-Construction How-To Guide. e-Construction. Florida Department of Transportation.

FHWA (2015). Implementation Plan Every Day Counts 3 | Innovation Initiative. e-Construction.

FHWA (2016a). Facilitation and Documenting of FHWA Division Office e-Construction Pilot Every Day Counts- -Construction. FHWA.

FHWA (2016b). Tennessee DOT, Alabama DOT, Missouri DOT, and Iowa DOT. e-Construction Peer-To-Peer Exchange.

FHWA (2017). Addressing Challenges and Return on Investment (ROI) for Paperless Project Delivery (eConstruction). FHWA.

FHWA. (2018). e-Construction Lead State Profiles [Online]. FHWA. Available: https://www.fhwa.dot.gov/construction/econstruction/leadprofiles.pdf [Accessed].

Geddes R. and Madison T. J. J. (2017). Fixing America's Roads \& Bridges: The Path Forward. Poclicy Analysis. The Committee for Economic Development of The Conference Board (CED).

George D. and Mallery P. (2011). SPSS for Windows step by step: A simple guide and reference, Boston, MA, Allyn \& Bacon.

Goforth C. (2015). Using and interpreting Cronbach's alpha. StatLab Articles [Online]. Available: https://data.library.virginia.edu/using-and-interpreting-cronbachs-alpha/.

Hasan A., Ahn S., Rameezdeen R. and Baroudi B. (2019). Empirical Study on Implications of Mobile ICT Use for Construction Project Management. Journal of Management in Engineering, 35, 04019029.

i-SCOOP. (2016). Digitization, digitalization and digital transformation: the differences [Online]. i-SCOOP. Available: https://www.i-scoop.eu/digitization-digitalization-digital-transformation-disruption/ [Accessed].

Ichniowski T. (2019). Infrastructure talk continuous, no action yet. Engineering News-Record. 990 Park Center Dr, Vista, CA: bnp media.

LeClair S. (2018). Product choices impact costs and lead times. Engineering News-Record. 990 Park Center Dr, Vista, CA: bnp media.

Lee S.-K. and Yu J.-H. (2012). Success model of project management information system in construction. Automation in Construction, 25, 82-93.

Lohr S. L. (2010). Sampling: Design and Analysis, Boston, MA, Brooks/Cole Cengage Learning.

Love P. E. D., Irani Z. and Edwards D. J. (2004). Industry-centric benchmarking of information technology benefits, costs and risks for small-to-medium sized enterprises in construction. Automation in Construction, 13, 507-524.

Lu Y., Li Y., Skibniewski M. J., Wu Z., Wang R. and Le Y. (2015). Information and Communication Technology Applications in Architecture, Engineering, and Construction Organizations: A 15-Year Review. Journal of Management in Engineering, 31, A4014010.

Mak S. (2001). A model of information management for construction using information technology. Automation in Construction, 10, 257-263.

Martínez-Rojas M., Marín N. and Vila M. A. (2015). The Role of Information Technologies to Address Data Handling in Construction Project Management. Journal of Computing in Civil Engineering, 30, 04015064.

Mohamed S. and Stewart R. A. (2003). An empirical investigation of users' perceptions of web-based communication on a construction project. Automation in Construction, 12, 43-53. 
Nitithamyong P. and Skibniewski M. (2003) Published. Critical success/failure factors in implementation of webbased construction project management systems. Construction Research Congress, 2003 Honolulu, HI. American Society of Civil Engineers, 1-8.

Nitithamyong P. and Skibniewski M. J. (2006). Success/failure factors and performance measures of web-based construction project management systems: Professionals' viewpoint. Journal of Construction Engineering and Management 132, 80-87.

Nitithamyong P. and Skibniewski M. J. (2007). Key Success/Failure Factors and Their Impacts on System Performance of Web-Based Project Management Systems in Construction. Journal of Information Technology in Construction, 12, 39-59.

O’Brien W. J., Mondragon F., Howe J., Sutton T., Hijazi F. and Young S. (2017). Real-Time Field Reporting Using Smart Devices-Phase II [Online]. Fiatech. Available: https://custom.cvent.com/F0D3FC83AB884EE1BAAC045EEDBF06C1/files/7b60431ee2584b69b1647 3fcbb324c34.pdf [Accessed].

Peterson's. (2019). College Information [Online]. Peterson's. Available: https://www.petersons.com/ [Accessed].

Prause J. (2016). Digitization vs. Digitalization - Wordplay or World View? [Online]. SAP. Available: https://news.sap.com/2016/05/digitization-vs-digitalization-wordplay-or-world-view/ [Accessed].

Ramsey F. L. and Schafer D. W. (2013). The Statistical Sleuth: A Course in Methods of Data Analysis, Boston, MA, Brooks/Cole, Cengage Learning.

Shah K., Mitchell A., Lee D. and Mallela J. (2017). Addressing Challenges and Return on Investment (ROI) for Paperless Project Delivery (e-Construction). FHWA/Construction/ Technologies and Innovation/ $e$ Construction. FHWA.

Shrout P. E. and Fleiss J. L. (1979). Intraclass correlations: Uses in assessing rater reliability. Psychological Bulletin, 86, 420-428.

Siddaway A. (2014). What is a Systematic Literature Review and How Do I Do One? Available: https://pdfs.semanticscholar.org/2214/2c9cb17b4baab118767e497c93806d741461.pdf?_ga=2.8237282 $2.1363188050 .1562800022-1520244306.1562800022$.

Sillars D. N., Ng E. H., Calvo-Amodio J., Capalbo S., Martin M., Jahanger Q. K., Zimmerman G., Hadziomerspahic A., Wang S. and Elatlasi R. (2017). Advanced Technology: Return on Investment at the Oregon Department of Transportation. Project 30530-16-14. Corvallis, OR: Oregon State University.

Stewart R. A. (2007). IT enhanced project information management in construction: Pathways to improved performance and strategic competitiveness. Automation in Construction, 16, 511-517.

Stewart R. A. and Mohamed S. (2003). Evaluating the value IT adds to the process of project information management in construction. Automation in Construction, 12, 407-417.

Stewart R. A. and Mohamed S. (2004). Evaluating web-based project information management in construction: capturing the long-term value creation process. Automation in Construction, 13, 469-479.

Sulankivi K. (2004). Benefits of Centeralized Digital Information Management in Multipartner Projects. Journal of Information Technology in Construction, 9, 35-63.

Tavakol M. and Dennick R. (2011). Making sense of Cronbach's alpha. International journal of medical education, 2, 53-55.

Teicholz P. (2013). Labor-productivity declines in the construction industry: Causes and remedies (another look). AECbytes Magazine. AECbytes.

Thorpe D. (2003). Online Remote Construction Management trials in Queensland Department of Main Roads: a participant's perspective. Construction Innovation, 3, 65-79. 
Tymvios N. and Gambatese J. A. (2016). Perceptions about Design for Construction Worker Safety: Viewpoints from Contractors, Designers, and University Facility Owners. Journal of Construction Engineering and Management, 142, 04015078.

US Census Bureau. (2017). Geographies [Online]. U.S. Department of Commerce. Available: https://www.census.gov/geographies/reference-files/2015/demo/popest/2015-fips.html [Accessed].

Vaughan J. L., Leming M. L., Liu M. and Jaselskis E. (2013). Cost-benefit analysis of construction information management system implementation: Case study. Journal of Construction Engineering and Management, 139, 445-455.

Weippert A., Kajewski S. L. and Tilley P. A. (2002). Internet-based information and communication systems on remote construction projects: a case study analysis. Construction Innovation, 2, 103-116.

Weisner K., Cawley B. and Sindlinger A. (2017). The Age of e-Construction. Public Roads. FHWA.

Woetzel J., Sridhar M. and Mischke J. (2017). The construction industry has a productivity problem - and here's how to solve it [Online]. MarketWatch. Available: https://www.marketwatch.com/story/the-constructionindustry-has-a-productivity-problem-and-heres-how-to-solve-it-2017-03-04 [Accessed].

Zhiliang M., Heng L., Shen Q. P. and Jun Y. (2004). Using XML to support information exchange in construction projects. Automation in Construction, 13, 629-637. 